\title{
Article \\ Conceptual Design Optimization of Autonomous Electric Buses in Public Transportation
}

\author{
Aditya Pathak ${ }^{1,2, * \mathbb{D}}$, Silvan Scheuermann ${ }^{1}$, Aybike Ongel ${ }^{1}\left[\right.$ and Markus Lienkamp ${ }^{2}$ \\ 1 TUMCREATE Limited, 1 Create Way, \#10-02 CREATE Tower, Singapore 138602, Singapore; \\ silvan.scheuermann@tum-create.edu.sg (S.S.); aybike.ongel@tum-create.edu.sg (A.O.) \\ 2 Institute of Automotive Technology, Technical University of Munich, Boltzmannstr. 15, \\ 85748 Garching, Germany; lienkamp@ftm.mw.tum.de \\ * Correspondence: aditya.pathak@tum-create.edu.sg
}

check for

updates

Citation: Pathak, A.; Scheuermann S.; Ongel, A.; Lienkamp, M. Conceptual Design Optimization of Autonomous Electric Buses in Public Transportation. World Electr. Veh. J. 2021, 12, 30. https://doi.org/ 10.3390/wevj12010030

Received: 25 January 2021

Accepted: 10 February 2021

Published: 18 February 2021

Publisher's Note: MDPI stays neutral with regard to jurisdictional claims in published maps and institutional affiliations.

Copyright: (c) 2021 by the authors. Licensee MDPI, Basel, Switzerland. This article is an open access article distributed under the terms and conditions of the Creative Commons Attribution (CC BY) license (https:// creativecommons.org/licenses/by/ $4.0 /)$.

\begin{abstract}
Autonomous electric buses (AEB) have widely been envisioned in future public transportation systems due to their large potential to improve service quality while reducing operational costs. The requirements and specifications for AEBs, however, remain uncertain and strongly depend on the use case. To enable the identification of the optimal vehicle specifications, this paper presents a holistic design optimization framework that explores the impacts of implementing different AEB concepts in a given set of routes/network. To develop the design optimization framework, first, a multi-objective, multi-criteria objective function is formulated by identifying the attributes of bus journeys that represent overall value to the stakeholders. Simulation models are then developed and implemented to evaluate the overall performance of the vehicle concepts. A genetic algorithm is used to find the concepts with the optimal trade-off between the overall value to the stakeholders and the total cost of ownership. A case study is presented of a single bus line in Singapore. The results show an improvement in the waiting time with the use of a smaller sized AEB with a capacity of 20 passengers. However, the costs and emissions increase due to the requirement of a larger fleet and the increase in daily distance traveled compared to a 94-passenger capacity AEB.
\end{abstract}

Keywords: vehicle concept optimization; autonomous buses; electric buses; public transportation

\section{Introduction}

Technological advances in electrification and automation are transforming the automotive industry as governments are seeking for sustainable public transportation solutions to improve transport efficiency, reduce traffic congestion, and minimize Greenhouse Gas (GHG) emissions. Following the electrification of urban buses to eliminate local emissions of nitrogen oxides and particulate matter, there has been a wide interest in automating urban city buses to promote a modal shift away from private car usage to ease traffic congestion [1,2].

Automation of public transit is expected to attract more users, as the service quality can be improved by decreasing the waiting and travel time of passengers [3] while reducing operational costs from the drivers' remuneration. To improve the service quality, operators can increase the frequency of buses or operate vehicles of smaller sizes to increase bus frequencies while reducing operating costs of traveling empty. Various projects, such as the DART [4] in Singapore and HEAT [5] in Hamburg, Germany, are therefore investigating the use of autonomous electric minibuses to complement existing public transport.

Several original equipment manufacturers (OEMs) are also focusing on developing autonomous buses of smaller capacities between 10-60 passengers such as the concepts from NAVYA [6], Easy mile EZ-10 [7], GRT shuttle [8] and SCANIA NXT [9]. Buses of different sizes and configurations are therefore expected in the prospective product portfolios of bus OEMs. 
In the pre-development phase of the automotive product development process, strategic decisions need to be made regarding the preliminary specifications of the vehicle. To minimize the development time, methods such as parametric modeling [10-12] and conceptual design optimization [13-16] are used to define the vehicle parameters in the early concept phase to find solutions that best meet the development objectives.

Vehicle concept optimization has been widely studied for the design of conventional, hybrid and electric passenger vehicle concepts [17]. Research has been conducted at different levels from the component level up to the entire vehicle concept. At the component level, the component type and size are optimized [18]. At the topology level, systems such as the powertrain $[19,20]$ and cooling [21] are optimized, and at the vehicle concept level, the entire vehicle concept is optimized based on multi-criteria design objectives $[15,16,22]$.

To optimize the overall vehicle concept, various studies have been conducted by Ziemann [23], Meurle [24], Weber [25], Wiedemann [14], and Schockenhoff [26] to identify the properties of vehicles that provide value to the user such as comfort, off-road performance, and top speed. The properties describe all the relevant aspects of the vehicle from the user's perspective and allows for the formulation of an objective function. The vehicle concept is, therefore, optimized to maximize the benefit to the user.

Wiedemann [27] identifies and develops a method to optimize seven properties of range, cost efficiency, passenger comfort, design, everyday suitability, lateral dynamics, and longitudinal dynamics for the design of electric passenger vehicles. Various methods such as pattern search, design of experiments, and evolutionary algorithms are further investigated to calculate the optimal vehicle specifications.

Matz [15] further develops a method to optimize passenger electric vehicle concepts in a multi-modal transport network using the properties identified in [27]. A multi-objective optimization is implemented that finds concepts with the optimal trade-off between the value to the user and total cost of ownership (TCO). The model uses the NSGA-II genetic algorithm to find the set of Pareto optimal solutions.

Vehicle concept optimization methods represent the state-of-research in the development of conventional and electric passenger vehicles. However, such methods have not been widely applied in the development of buses. The majority of publications on electric buses study and compare the lifecycle costs and GHG emissions of Battery-Electric Buses against Diesel and Hybrid powertrains and discuss the potential of using alternative powertrain technologies [28-30]. Due to the high costs of the battery technology and charging infrastructure, other studies [31-33] investigate the influence of the battery size, charging method such as depot and opportunity charging, on costs and analyze the optimal vehicle and charging schedules $[34,35]$.

A holistic design optimization of buses has not been conducted. Furthermore, the influence of the automation of buses on the vehicle concept design has also not been investigated in detail. Therefore, this paper presents a holistic design optimization framework to identify the optimal autonomous electric bus (AEB) concepts for a given set of routes/network. The properties of AEBs are first investigated to formulate the objective function for the optimization. A simulation framework is developed to enable the calculation and evaluation of AEB concepts in a public transport network. Finally, a case study is presented on a bus route in Singapore to compare the impacts of different vehicle sizes on the costs, emissions, and overall value to the stakeholders.

\section{Methodology}

The overall methodology of this paper consists of three main parts, as shown in Figure 1. First, the properties of AEBs are determined from the perspective of the users, bus operators, and government authorities. Next, an objective function is formulated by identifying value functions representing the correlation between the value to the stakeholders and the technical specification of the properties. Lastly, in the implementation step, simulation models are developed and implemented to evaluate different vehicle concepts in a public transport network. 
Derivation of

Properties
Formulation of the

Objective Function
Implementation of

Simulation Models

Figure 1. Overview of the overall methodology.

\subsection{Derivation of Properties}

In the automotive development process, the overall system design requirements are described from the stakeholders' perspective $[25,36]$. The requirements are structured into three levels [26] of properties, attributes, and technical specifications. The properties describe the overall qualities that the user perceives and comprises of attributes that are directly quantifiable by a technical specification such as top speed and acceleration time.

To derive the overall properties for the development of AEBs, first, a stakeholder and persona analysis is conducted to analyze the different bus users and their needs during various phases of the bus journey from arrival and boarding at the bus stop to traveling and alighting at the destination stop [37]. Subsequently, a functional assessment is carried out to identify the attributes of the bus journey that would influence the stakeholders preferences and satisfaction. Using a taxonomy approach, the attributes are categorized to form the properties. Nine property fields, shown in Table 1, are identified through the categorization of the attributes: service performance, accessibility, comfort, functionality, information, safety, longitudinal dynamics, environmental performance, and costs.

Table 1. Identified properties and attributes of AEBs.

\begin{tabular}{cc}
\hline Property & Attributes \\
\hline Service Performance & Waiting time \\
Travel time \\
Seat availability
\end{tabular}

Two online surveys, a stated preference, and a pairwise-comparison of the properties were developed to find the stakeholders' preferences towards the attributes and obtain the weighting factors for the properties. The surveys were disseminated by distributing QR-codes directly to bus passengers in Singapore, emails to bus operators, and social 
media platforms. A total of 225 responses were received and analyzed using the Analytic Hierarchy Process to calculate the weighting factors of the properties and attributes. The survey questionnaires and responses are described in detail in [37].

\subsection{Formulation of the Objective Function}

To conduct a holistic design optimization of AEBs, a multi-criteria objective function, $y$, is formulated using the derived properties. The objective function consists of two objectives shown in Equations (1) and (2). The first objective $y(1)$ maximizes the property fulfillment and is calculated using the weighted $(W)$ sum of the property value. The second objective $y(2)$ minimizes the TCO, for a vector $x$ that consists of the vehicle parameters. The weights for both the properties and attributes are obtained from the surveys analyzed in the preceding step [37].

$$
\begin{aligned}
y(1)=\max ( & f \text { ServicePerformance }(x)) * W_{\text {ServicePerformance }} \\
& +f(\text { Accessibility }(x)) * W_{\text {Accessibility }}+f(\text { Comfort }(x)) \\
& * W_{\text {Comfort }}+f(\text { Functionality }(x)) * W_{\text {Functionality }} \\
& +f(\text { Information }(x)) * W_{\text {Information }}+f(\text { Safety }(x)) \\
& * W_{\text {Safety }}+f(\text { LongitudinalDynamics }(x)) \\
& * W_{\text {LongitudinalDynamics }} \\
& +f(\text { EnvironmentalPerformance }(x)) \\
& \left.* W_{\text {EnvironmentalPerformance }}\right) \\
& \quad y(2)=\min (\text { TotalCosts }(x))
\end{aligned}
$$

Each property is calculated by taking the weighted sum of its comprising attributes shown in Table 1 . The attributes are evaluated using value functions that correlate how desirable the value of the technical specification is, in the view to the stakeholders on a scale of $1-10$. The value functions are derived by benchmarking existing vehicles and analyzing vehicle standards and public transport satisfaction surveys. Figure 2 shows instances of the value functions used to quantify the attributes. A logistic function is used to represent the value functions rather than a linear correlation as proposed by Aigner [38], as the added value to the user reduces with increasing satisfaction. For example, for the attribute legroom, shown in Figure 2c, as the seat pitch increases, the value to the passenger increases exponentially up to a seat pitch of $750 \mathrm{~mm}$. Any further increase in seat pitch does not provide additional satisfaction to the passenger. The curve, therefore, flattens out towards the end points.

However, for some attributes, the technical specification is not continuous and takes discrete values-for example, the attribute wheelchair zones in Figure 2f. The value function is modeled using a step function that represents value to the user in discrete steps based on the number of wheelchair zones in the vehicle.

To determine the optimization variables, a correlation matrix is used to qualitatively correlate the vehicle parameters listed in $[39,40]$ with the identified attributes in Table 1, on a 3-point scale of strong, weak, and no correlation. The parameters with strong correlations are specified to be the optimization variables and are presented in Table 2 along with lower and upper bounds. 


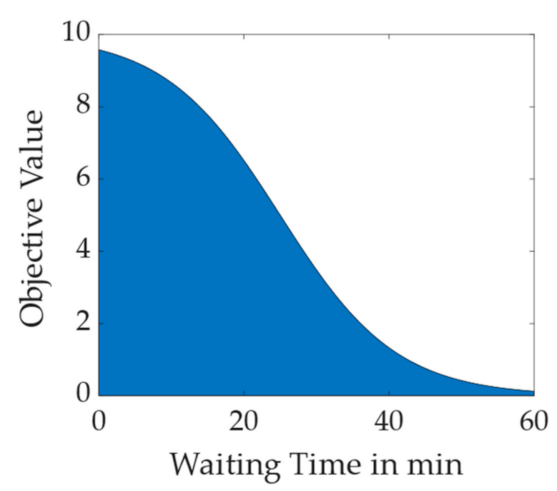

(a)

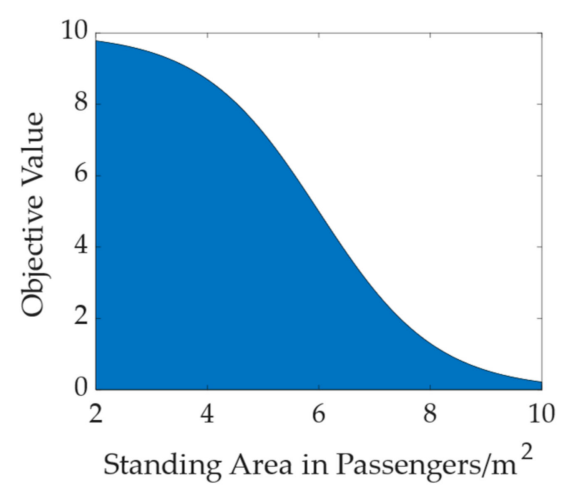

(d)

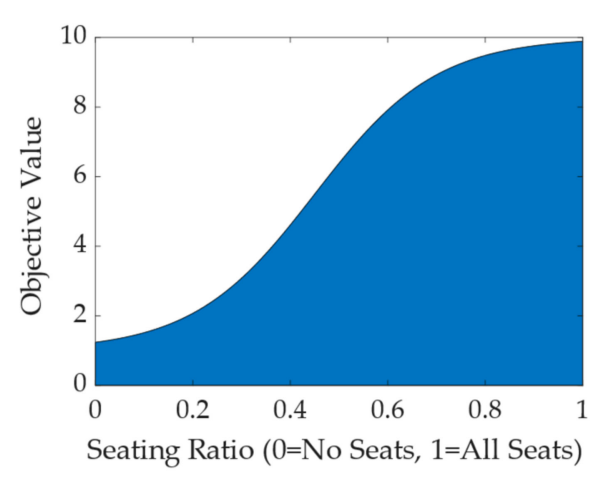

(b)

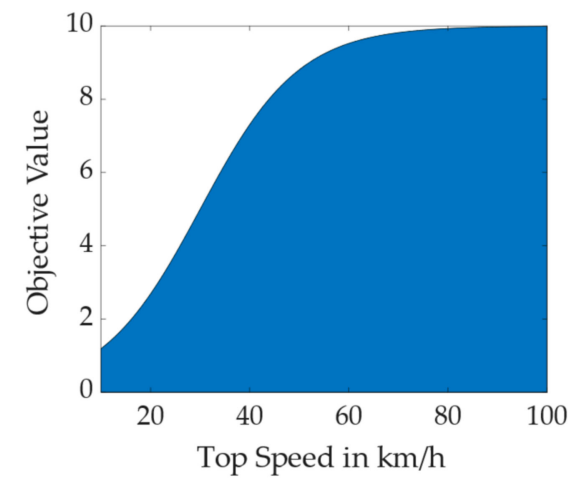

(e)

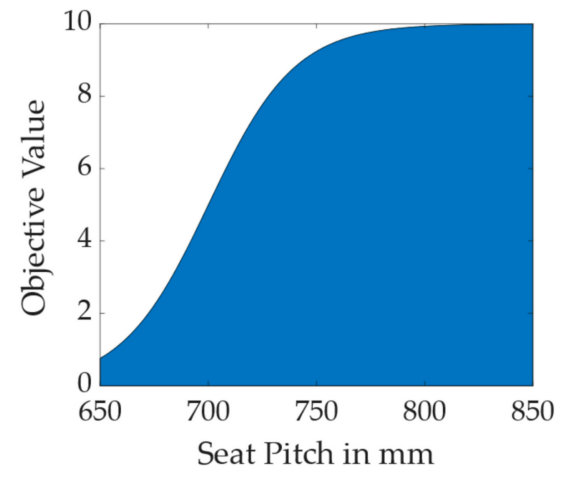

(c)

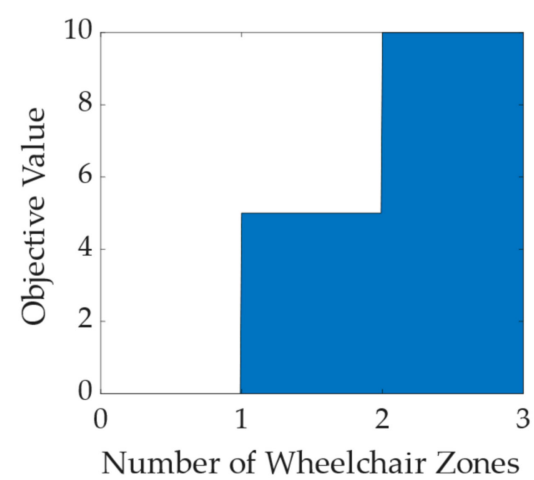

(f)

Figure 2. Value Functions showing the correlation between the objective value and technical specifications. Value function of (a) waiting time, (b) seating ratio, (c) seat pitch, (d) standing space, (e) vehicle top speed, (f) wheelchair zones.

Table 2. Optimization parameters of the vehicle concept.

\begin{tabular}{cccc}
\hline Vehicle Parameters & Lower Bound & Upper Bound & Type \\
\hline Vehicle Height & $2100 \mathrm{~mm}$ & $3000 \mathrm{~mm}$ & Continuous \\
Vehicle Length & $5000 \mathrm{~mm}$ & $13000 \mathrm{~mm}$ & Continuous \\
Vehicle Width & $2500 \mathrm{~mm}$ & $2600 \mathrm{~mm}$ & Continuous \\
Interior Layout & Layout 1 & Layout 2 & Categorical \\
Wheelbase & $2500 \mathrm{~mm}$ & $9000 \mathrm{~mm}$ & Continuous \\
Seat Pitch & $650 \mathrm{~mm}$ & $850 \mathrm{~mm}$ & Continuous \\
Seat Width & $400 \mathrm{~mm}$ & $550 \mathrm{~mm}$ & Continuous \\
Standing Space & 2 Passengers $/ \mathrm{m}^{2}$ & 8 Passengers $/ \mathrm{m}^{2}$ & Continuous \\
Powertrain Topology & Topology 1 & Topology 2 & Categorical \\
Total Power & $40 \mathrm{~kW}$ & $400 \mathrm{~kW}$ & Continuous \\
Gear Ratio & 1 & 30 & Continuous \\
Battery Capacity & $30 \mathrm{kWh}$ & $350 \mathrm{kWh}$ & Continuous \\
Wheelchair Zones & 0 & 2 & Discrete \\
Number of Doors & 1 & 2 & Discrete \\
\hline
\end{tabular}

\subsection{Implementation of Simulation Models}

To evaluate the objective function in Equations (1) and (2), a simulation framework is developed to calculate the property fulfillment and the total costs. The model is implemented in MATLAB and solved using an optimization algorithm. As the objective function is non-linear, the Non-Dominated Sorting Genetic Algorithm (NSGA-II) [41] is used for the optimization.

Figure 3 shows the overall framework which consists of the implemented models. For a given set of routes, a vehicle concept is defined and created using a parametric packaging model according to the design parameters of the optimization. Next, the 
schedule for the derived concept is analyzed and through a route simulation the impacts on the passenger waiting time and vehicle occupancy levels are analyzed. A longitudinal dynamics simulation subsequently simulates the energy consumption of the concept. A vehicle assignment model then analyzes the vehicle concept's impact on the fleet size, and total distance traveled to calculate the TCO and life cycle emissions accurately. The following sections of the methodology describe the implemented simulation models to evaluate the attributes in the objective function and perform the overall optimization.

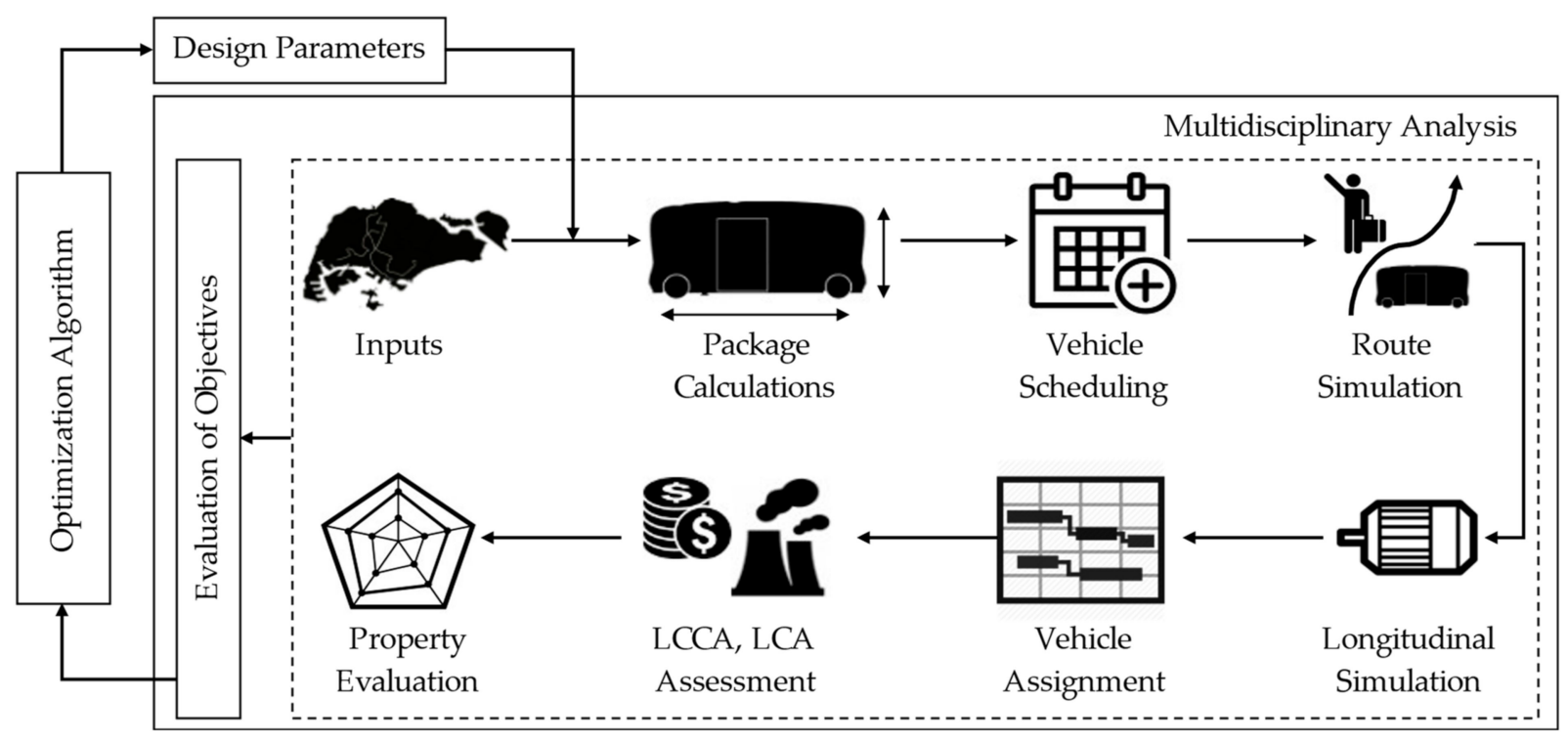

Figure 3. Overall simulation framework to evaluate the objective function.

\subsubsection{Inputs}

The required inputs to conduct the simulation consist of the route data, the driving cycle for the powertrain simulation, the charging method-depot charging or opportunity charging, and the corresponding charger power. The route data consists of the passengers' hourly origin-destination matrix along the route, inter-stop distance and travel times between bus stops, and distance and time matrix between the depots and route termini.

For the routes analyzed in this work, the input data is obtained from the fare card dataset provided by Singapore's Land Transport Authority. The data is parsed to obtain the route level origin-destination matrices of the passengers and inter-stop distance and travel times.

\subsubsection{Package Calculation}

At each iteration of the optimization, a vehicle package calculation is first conducted. The packaging model creates a new vehicle concept by defining the interior layout and component positions using dimensional chains. The vehicle packaging model is provided by Sethuraman [39] which can create the vehicle package for buses of lengths 5 to $13 \mathrm{~m}$. The model is adapted and parameterized according to the optimization parameters in Table 2.

The model further calculates the mass and dimensions of the components. The battery mass and volume are calculated using the gravimetric and volumetric energy densities $[15,22]$. The inverter, motor, and transmission mass are calculated using regression functions from $[42,43]$. The mass for the axle assembly which includes, the axle, suspension, and brakes, is obtained from the technical data sheet of ZF axles [44] and the selection is made using the vehicle's sprung mass [45]. An empirical function is further used to obtain the cooling power and auxiliary power consumption of the air-conditioning system based on the vehicle's passenger capacity [45]. 
In addition to the component sizing and positioning, the packaging model checks for constraint violations of overlapping dimensions if the components' installation space is insufficient. The output from the packaging calculation consists of the concept's vehicle specification, which includes the passenger capacity, number of seats, seating-standing ratio, front, and rear overhangs, curb mass, gross vehicle mass, bill of components, and component specifications. Furthermore, the model allows for the visualization of the vehicle concept during postprocessing, as shown in Figure $4 \mathrm{a}, \mathrm{b}$ of a $6 \mathrm{~m}$ AEB and $12 \mathrm{~m}$ AEB, respectively.

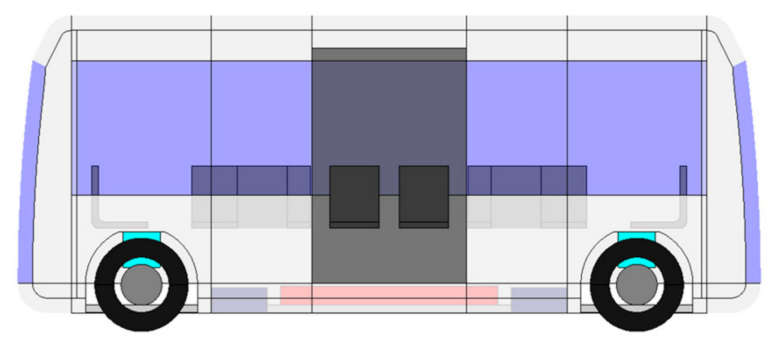

(a)

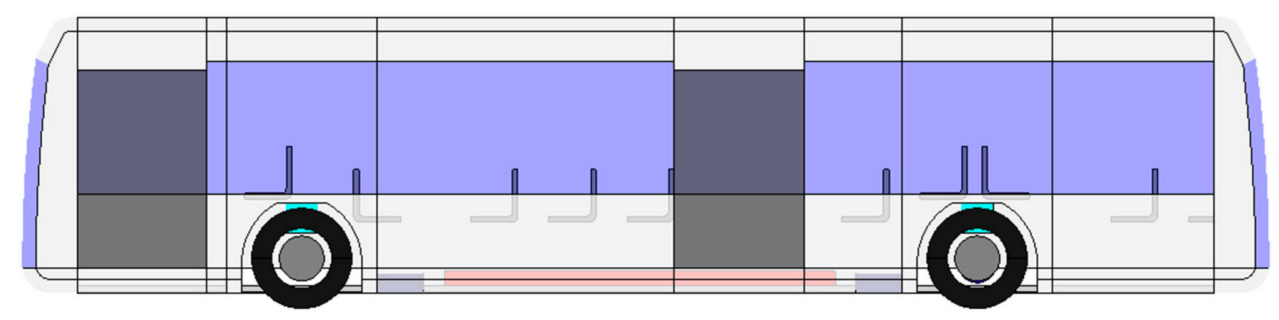

(b)

Figure 4. Vehicle package visualization of a $6 \mathrm{~m}$ AEB (a) and $12 \mathrm{~m} \mathrm{AEB} \mathrm{(b).}$

\subsubsection{Vehicle Scheduling}

Following the packaging calculation, the timetable of the vehicle concept is evaluated using a two-step method described by Ceder [46], of frequency determination and departure time calculation. The frequency for each hour is calculated using Equation (3). Where $F$ is the frequency, $P_{m j}$ is the maximum passenger load, $d_{o j}$ is the desired occupancy, and $F_{\min }$ is the minimum frequency at time period $j$.

$$
F=\max \left(\frac{P_{m j}}{d_{o j}}, F_{m i n}\right)
$$

The departure times from the termini are subsequently calculated using the graphical method proposed by [46]. In this method, the cumulative hourly frequency is plotted against time, as shown in Figure 5. The time at which each vehicle departure intersects with the curve is the resulting departure time for the vehicle from the route terminal. The first departure time for each route can be predefined or calculated from the graph. The calculation is repeated for each direction and the remaining routes in the inputs. 


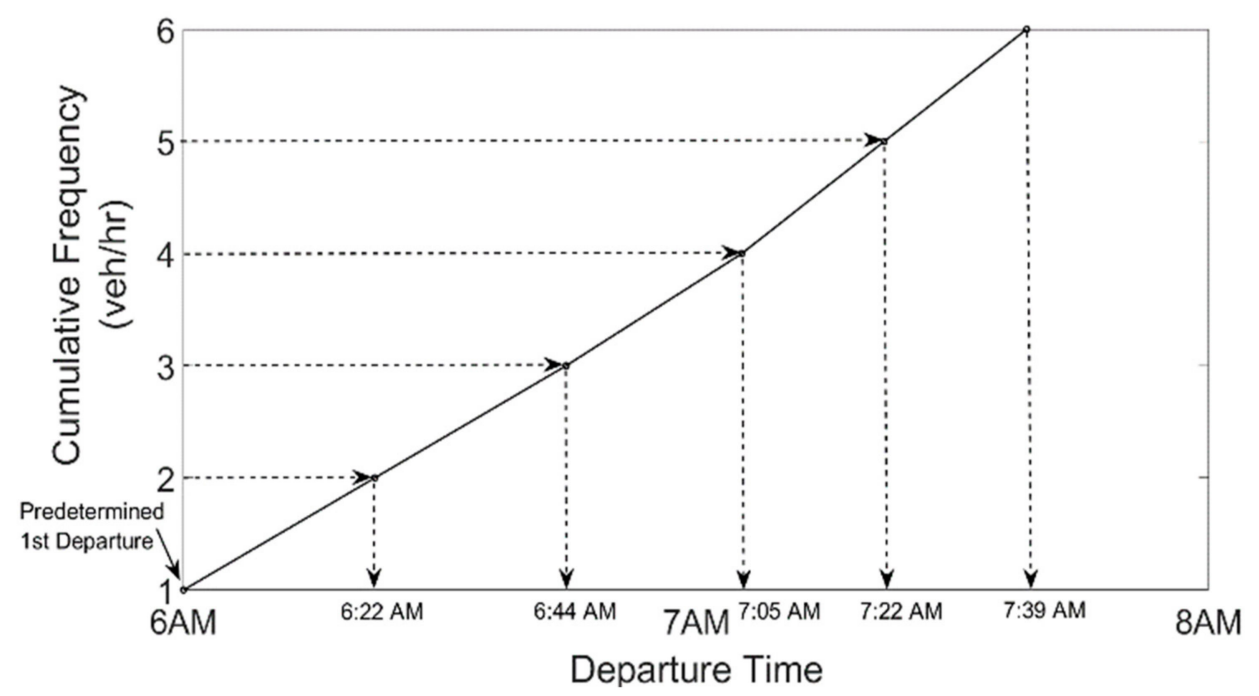

Figure 5. Determination of departure times using the graphical method in [46].

\subsubsection{Route Simulation}

A route simulation is conducted to obtain the passenger occupancy levels in each vehicle trip and calculate the waiting and in-vehicle time of the passengers. The route simulation is conducted in three steps. First, the boarding passengers' arrival time at each bus stop is calculated by modeling the passenger arrival process as a Poisson process. Next, the destination stop for these passengers is obtained from the origin-destination matrix of the route. The dispatch of the vehicles and boarding and alighting process of the passengers is then simulated.

The vehicles are dispatched from their respective termini according to the departure times obtained from the calculated timetable. The arrival time of the vehicle at the next stop is subsequently calculated using the inter-stop travel times. The vehicle occupancy at the next stop is updated based on the boarding and alighting passenger counts. The alighting passenger counts are known in prior according to the passengers' destination onboard of the vehicle. The number of boarding passengers is calculated from the waiting passenger count at the bus stop. The vehicle's dwelling time at the stop is calculated using the boarding and alighting passenger counts using the empirical model in [47]. The calculation is repeated for the following stops and subsequent vehicle departures for all routes. The vehicle occupancy profiles for each trip, waiting, in-vehicle, travel times of the passengers, and the total passenger-km traveled are calculated through the route simulation.

\subsubsection{Longitudinal Dynamics Simulation}

To evaluate the performance of the powertrain design of the vehicle concept, a longitudinal dynamics simulation (LDS) is conducted using the driving cycle, vehicle specification, passenger occupancy, and auxiliary power consumption of the air-conditioning system. The LDS model developed in [48] is implemented within the framework and simplified to analyze two powertrain architectures shown in Figure 6a, with a single central motor at the rear axle and dual wheel-hub motors at the rear axle (b). Due to the low-floor requirement and insufficient packaging space at the vehicle front axle, powertrain architectures with motors at the front axle are not feasible and are therefore excluded. The LDS model evaluates the energy consumption, acceleration performance, gradeability, and vehicle range for a vehicle concept using the specified driving cycle. 


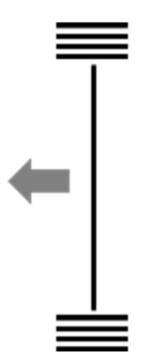

1: Differential

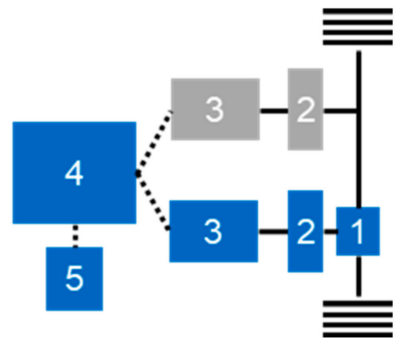

2: Gearbox

(a)

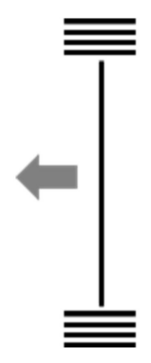

3: Electric motor and inverter

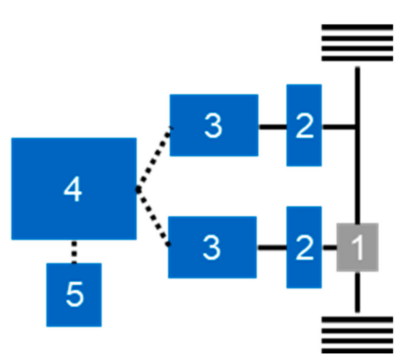

4: Battery 5: Auxiliaries

(b)

Figure 6. Powertrain Architectures of single motor rear wheel drive (a) and (b) dual wheel-hub motors.

\subsubsection{Vehicle Assignment}

A vehicle assignment model is developed to evaluate the required fleet size and the total daily distance traveled due to the change in the number of scheduled trips for different vehicle concepts. A mixed integer linear program is formulated to optimally allocate the scheduled trips to each vehicle such that the fleet size and the total distance traveled by the vehicles is minimized.

The model can simulate both depot charging and terminal charging strategies. In the depot charging model, vehicles can only charge between trips by visiting the depot. However, additional energy costs are incurred to travel back and forth from the depot to the termini. In the terminal charging calculation, the vehicles can charge at the route termini before or after a trip or continue to the next trip without charging. The vehicle assignment model finds the cost-optimal allocation of the trips to the vehicles while ensuring the charge levels do not fall below a specified state of charge (SOC).

The mathematical formulation of the model is described by the objective function in Equation (4). Each scheduled trip $i$ to $n$ is represented as a node. An arc $x_{i j}$ connects trips $i$ and $j$ if a vehicle completing trip $i$ can perform trip $j$. The connection is feasible only if the ending time of trip $i$ and the time taken to travel to the departing terminal of trip $j$ is less than the departure time of trip $j$. In addition, the depot is represented by node $(n+1)$ which has arcs to and from all scheduled trips, which represent the 'pull-out' and 'pull-in' operations, respectively.

Each arc $x_{i j}$ between scheduled trips $\mathrm{i}$ and $\mathrm{j}$ has a cost $c_{i j}$ associated with it equal to the costs arising from the energy consumption during the trip $i$ and from driving to the terminal of the next trip or the depot $j$. The 'pull-out' arcs that originate from the depot have a cost of requiring a new vehicle in addition to the energy cost of driving from the depot to the terminal of trip $j$.

The constraints in the assignment model are described in Equations (5)-(8). Equations (5) and (6) ensure that a trip cannot be covered more than once. Constraint (7) ensures that the number of vehicles arriving back at the depot should be the same as the number that departed from the depot. Constraint (8) ensures that the vehicle is only assigned trips if it has sufficient charge, $q$, to cover the trip and drive back to the depot. The variables $u$ and $v$ represent the energy consumption of trip $i$ and the deadheading trip $i j$ respectively, and $Q$ is the battery capacity of the vehicle. The variables are shown in Equation (9) of $x_{i j}$ representing the use of the arc, and $q_{i}$ the charge level of the vehicle at each node, which is calculated during the optimization.

$$
\begin{gathered}
\min \sum_{i=1}^{n+1} \sum_{j=1}^{n+1} c_{i j} x_{i j} \\
\sum_{j=1}^{n+1} x_{i j}=1 \quad \forall i=1,2, \ldots, n
\end{gathered}
$$




$$
\begin{gathered}
\sum_{i=1}^{n+1} x_{i j}=1 \forall j=1,2, \ldots, n \\
\sum_{i=1}^{n} x_{i, n+1}-\sum_{j=1}^{n} x_{n+1, j}=0 \\
q_{j} \leq q_{i}-x_{i j} u_{i}-x_{i j} v_{i j}+\left(1-x_{i j}\right) Q \\
x_{i j} \in\{0,1\}, q_{i} \in\left\{Q_{m i n}, Q\right\}
\end{gathered}
$$

Figure 7 shows the output from the vehicle assignment calculation. For each vehicle in the fleet, the schedule, whether it is performing a timetabled trip, an off-service trip, or is waiting/charging along with the SOC over the day, is obtained as shown in Figure 7 (top). Similarly, the trips assigned to the vehicle and terminals visited by the vehicle are obtained, as shown in Figure 7 (bottom). The calculation, therefore, allows for an accurate calculation of the total distances traveled and energy consumed by all the vehicles.
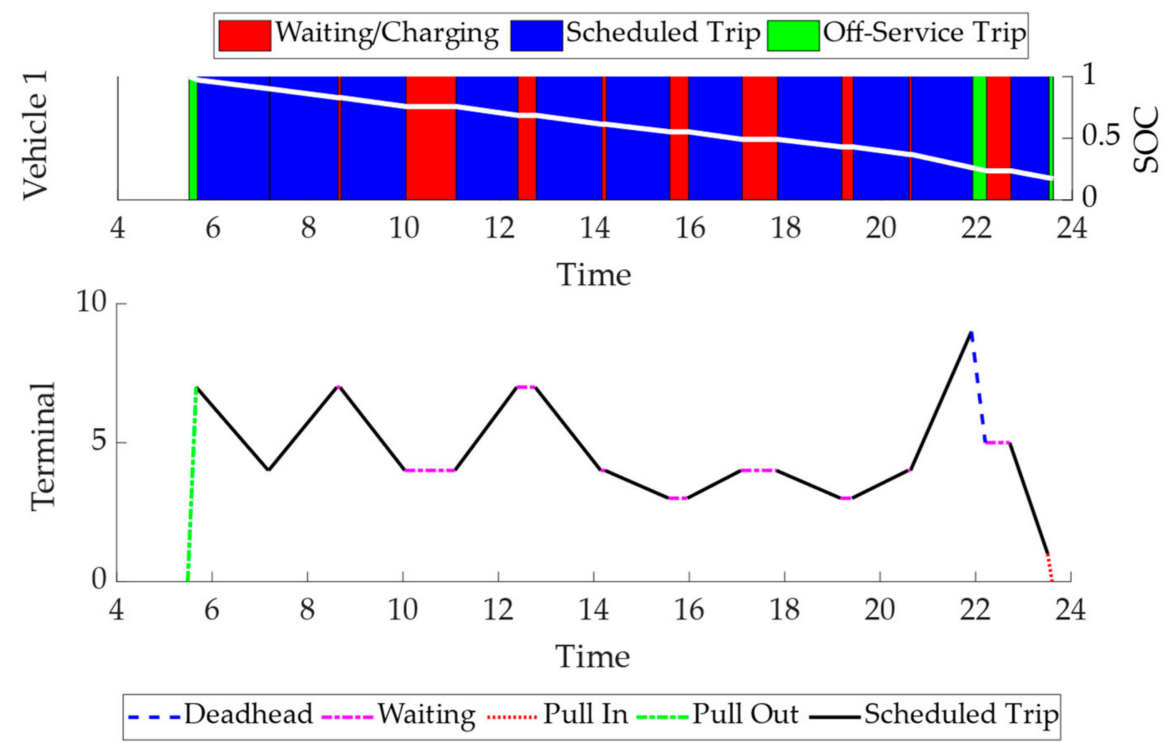

Figure 7. Showing the vehicle schedule and the state of charge (top), and the location and trips assigned to the vehicle during the day (bottom).

\subsubsection{Lifecycle Cost Assessment (LCCA) Model}

The LCCA model is used to evaluate the TCO of the vehicles by calculating the net present value (NPV) of the incurred costs during the lifetime of the vehicles. The TCO calculation follows the approach of Ongel [49] and is comprised of the acquisition, energy, battery replacement, cleaning, maintenance, insurance, road tax, and end-of-life costs. The model is adapted to evaluate the TCO of the fleet to allow for a fair cost comparison of vehicles of different sizes since a smaller passenger capacity vehicle would have a lower vehicle acquisition cost. However, a higher number of vehicles would be required to serve the same passenger demand.

The acquisition cost of the vehicle concept is calculated from the component costs, to which the additional expenditures arising from the assembly, labor, and energy costs are added. The component costs are calculated using correlations developed in [19] for the motor, inverter, and gearbox, and battery [50]. The costs of the axle, body, interior, and structure are estimated using the component mass, material mix, and raw material costs according to the method developed by Fuchs [51]. Costs of the sensors, cameras, and processing unit for autonomous driving hardware is taken from [49].

The energy costs are calculated using a fixed electricity price [52] and the total energy demand obtained from the vehicle assignment calculation. Costs due to the battery re- 
placement are estimated by calculating the number of battery packs required during the vehicle's lifetime. The calculation is based on the cycle life of the battery and the energy throughput calculated in the LDS. The costs from cleaning, maintenance, insurance, road tax, and end-of-life are calculated according to the described methods in [49].

Using the NPV approach, the annual costs over the assumed vehicle lifetime of 17 years is calculated and discounted to present value to obtain the TCO. The cost is further normalized by the total passenger-km traveled to calculate the total costs in SGD/passenger-km.

\subsubsection{Lifecycle Assessment Model (LCA)}

A scalable LCA model provided by [53] is used to analyze the GHG emissions of the vehicle concepts during the phases of production, distribution, use phase, and end-of-life. The model is developed from the Umberto-LCA [54] software, which uses the lifecycle inventory databases from Ecoinvent-version 3.5 [55]. The model calculates the production phase emissions of obtaining and converting raw materials into finished components based on the component's mass and material mix. The component mass and material composition for the body, structure, chassis, powertrain, and cooling are estimated from the packaging model. The emissions during the distribution of the vehicles to Singapore is further calculated from the Ecoinvent database.

To calculate the emissions in the use phase, a Well-to-Wheel assessment is done, which consists of the Well-to-Tank (WTT) and Tank-to-Wheel (TTW) stages. Since the vehicle concepts analyzed are electric, the TTW emissions are assumed to be zero. The WTT emissions are calculated based on the emissions in the electricity production, using the energy mix of Singapore [56,57] and the vehicle fleet's total energy consumption determined in the vehicle assignment calculation. The use-phase emissions are further calculated over the assumed vehicle lifetime of 17 years.

Lastly, the vehicles' end-of-life emissions are estimated due to energy use in material recycling and scraping processes. Based on the component mass, material composition, and material recycling rates [58-61], the processes' energy demand and emissions are calculated. The total emissions over the vehicles' lifetime are then calculated and normalized by the total passenger- $\mathrm{km}$ to calculate the emissions in $\mathrm{g}-\mathrm{CO}_{2} /$ passenger-km.

\subsubsection{Property Evaluation and Parameter Variation}

In the last step of the calculation, the objective function is evaluated using each attribute's value functions and the technical specifications obtained from the preceding calculations. A parameter variation is conducted at the end of each generation by the NSGA-II algorithm through a selection, cross-over and mutation operation on the current generation's population to calculate the vehicle parameters for the next generation. Furthermore, solutions that violate the constraints are removed during the selection operation. The optimization constraints are geometric inequalities that ensure that the component dimensions do not exceed the installation space and prevent any geometric overlap between components.

\section{Case Study}

Using the developed model, a case study is conducted on a single bi-directional bus route in Singapore to find the Pareto optimal concepts and analyze the vehicle's impacts on costs, property fulfillment, emissions, and powertrain design.

The bus route analyzed in the case study is $16.2 \mathrm{~km}$ in length and is shown in Figure 8 . The Bus rapid transit (BRT) driving cycle [62] is used as the speed profile to calculate the vehicle's energy consumption in the LDS simulation, and a depot charging operation is analyzed with $150 \mathrm{~kW}$ chargers available only at the depot. 


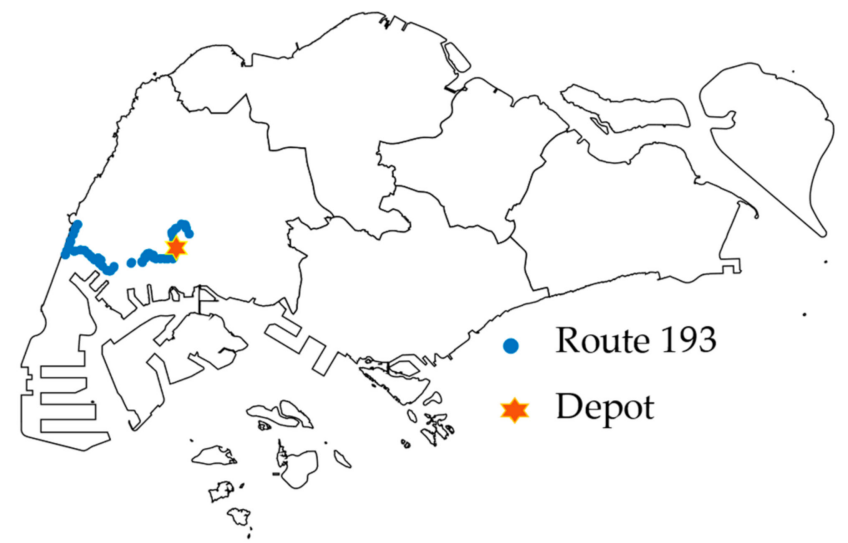

Figure 8. Route analyzed in this case study and the location of the depot.

\section{Results}

The results of the design optimization are presented in this section. Using the genetic algorithm, the optimal solutions of vehicle concepts are calculated for the analyzed route. Figure 9a depicts the Pareto front showing the optimal trade-off between the property fulfillment and the TCO. The property fulfillment represents the value to the stakeholders on a scale of 0 to 10 .

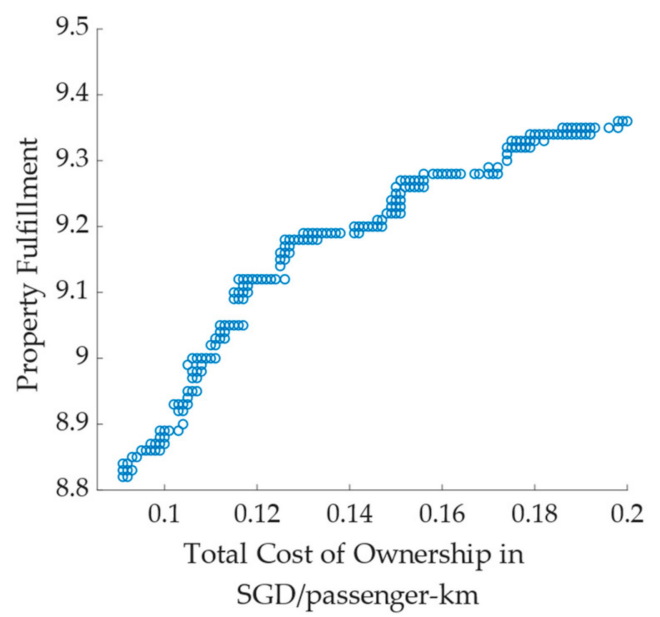

(a)

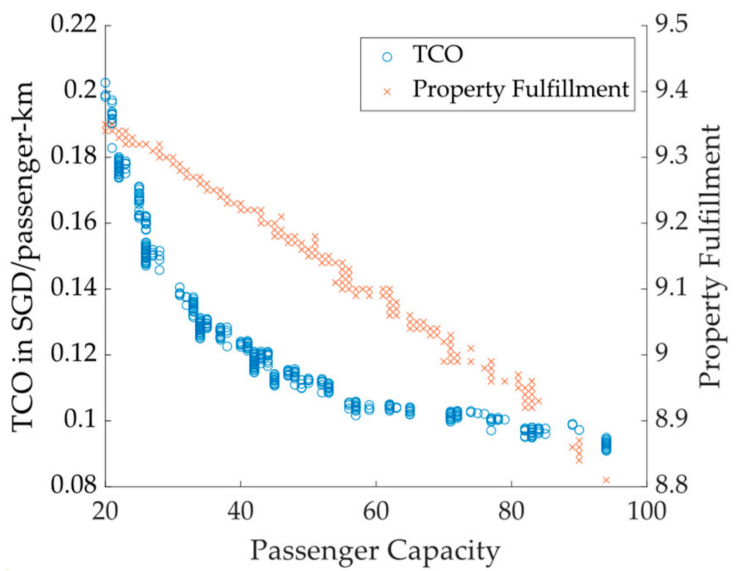

(b)

Figure 9. (a) Pareto optimal solutions of the vehicle concepts for the analyzed route. (b) The effect of vehicle size on the costs and value to the users.

Figure $9 \mathrm{~b}$ shows the influence of the vehicle size on the TCO and property fulfillment. Smaller vehicles have a higher property fulfillment value primarily due to improvements in the service performance attributes. Therefore, the property fulfillment increases to 9.35 for a vehicle size of 20 passengers compared to 8.81 for a 94-passenger vehicle. However, the total costs for the 20-passenger vehicle increase to $0.201 \mathrm{SGD} /$ passenger- $\mathrm{km}$ from $0.091 \mathrm{SGD} /$ passenger-km.

The TCO increases for the smaller vehicle sizes due to the larger fleet size and the increase in distance traveled by the fleet per day as shown in Figure 10a,b respectively. The fleet size increases from 16 to 69 vehicles while the distance traveled per day increases from 1280 to $5988 \mathrm{~km}$ for vehicle sizes of 94 and 20 passengers, respectively. 


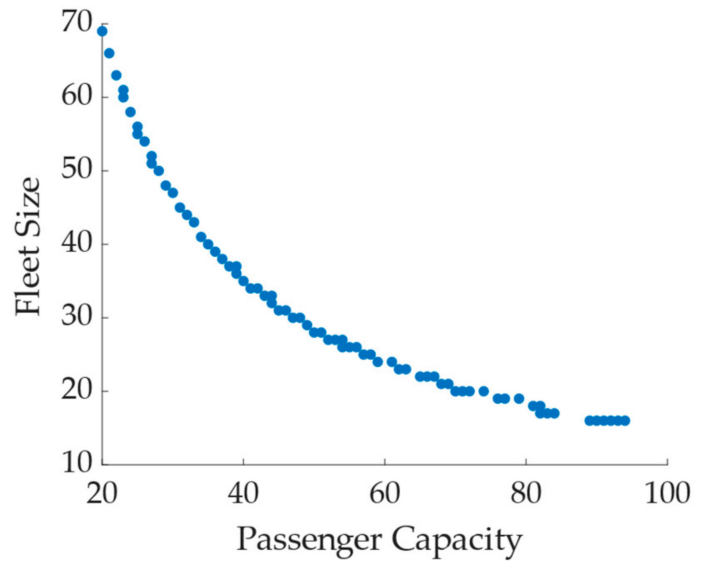

(a)

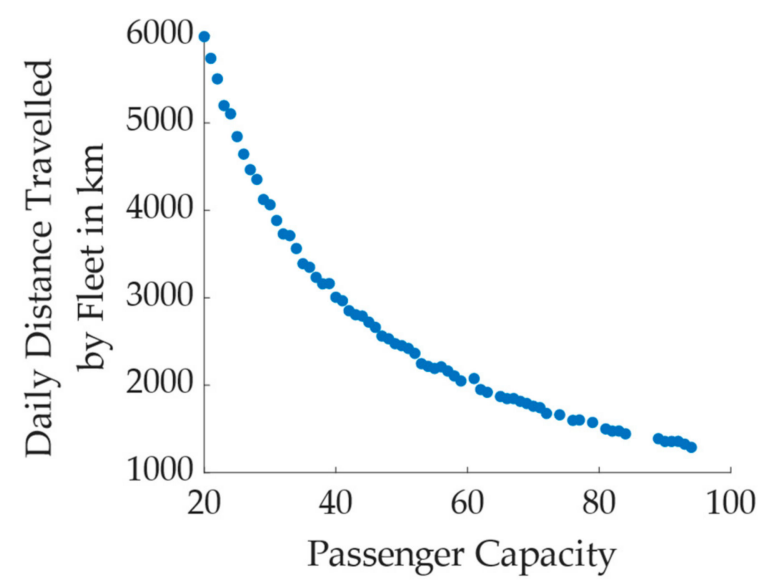

(b)

Figure 10. Influence of vehicle size on (a) fleet size and (b) on distance traveled per day.

The waiting time for the passengers however reduces from $18 \mathrm{~min}$ to around $6 \mathrm{~min}$ for the smaller vehicle size of 20 passengers. The overall service performance can therefore be significantly improved with the use of small capacity vehicles for the analyzed route. Figure $11 b$ shows how the number of timetabled trips changes with the vehicle size. The scheduled trips increase from 75 trips for 94-passenger vehicle to 340 trips for a 20-passenger vehicle. The scheduling algorithm calculates the bus frequencies according to the passenger demand at each hour and the vehicle's desired occupancy/seating capacity. Therefore, the number of scheduled trips significantly increases for smaller vehicle capacities, as seen in Figure 11b.

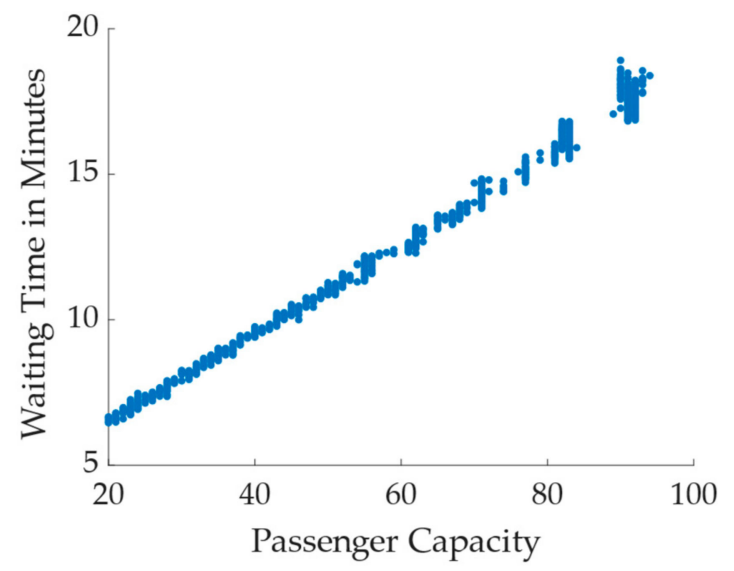

(a)

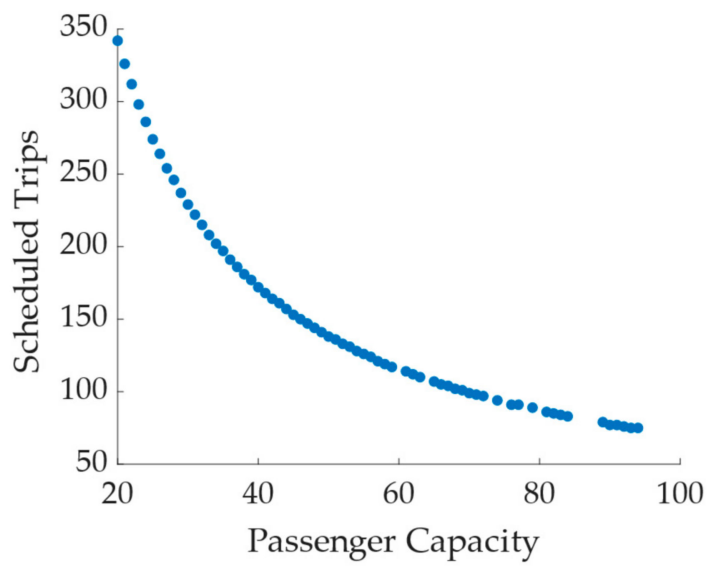

(b)

Figure 11. Influence of vehicle size on (a) passenger waiting time, and (b) number of scheduled trips.

Figure 12a shows the influence of the vehicle size on energy consumption. For the analyzed driving cycle, the vehicle's energy consumption increases linearly from $0.45 \mathrm{kWh} / \mathrm{km}$ for a 20-passenger vehicle to $1.35 \mathrm{kWh} / \mathrm{km}$ for a 94 -passenger vehicle. However, considering the overall fleet, the 20-passenger vehicle has a higher energy consumption of $0.12 \mathrm{kWh} /$ passenger- $\mathrm{km}$, due to the longer distances traveled, compared to $0.08 \mathrm{kWh} /$ passenger-km for a 94-passenger vehicle. 


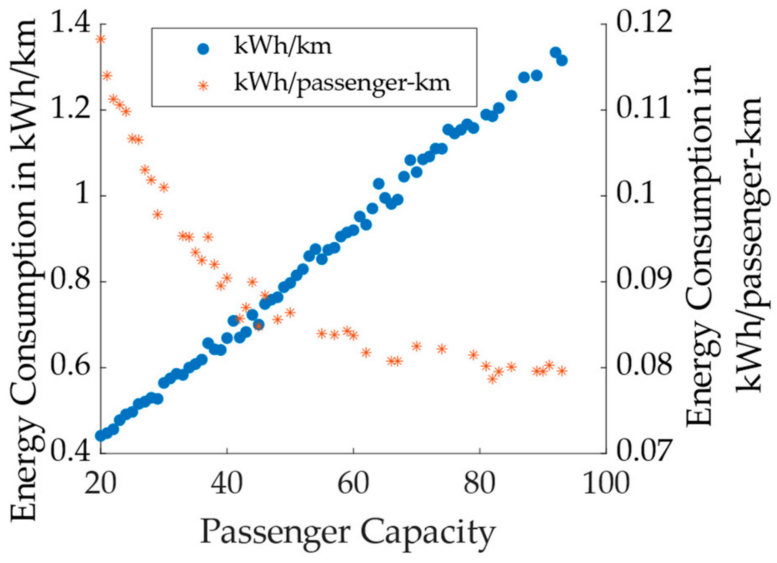

(a)

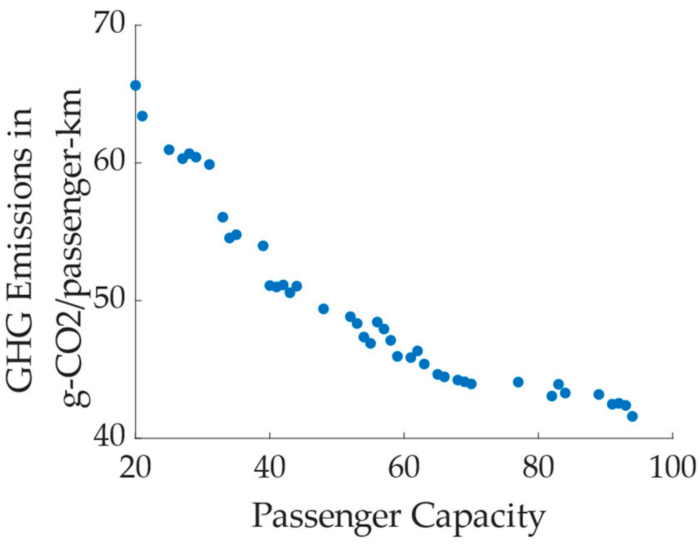

(b)

Figure 12. Influence of vehicle size on (a) energy consumption (b) GHG emissions.

Similarly, due to the increase in energy consumption, the GHG emissions of smaller vehicles also increase from 41.5 to $65.6 \mathrm{~g}-\mathrm{CO}_{2}$ / passenger- $\mathrm{km}$ for vehicle sizes of 94 and 20 passengers, respectively, as shown in Figure 12b.

Figure 13 shows the required motor power and battery capacity for different vehicle sizes. In Figure 13a, all feasible combinations of installed motor power simulated for different vehicle sizes are shown. The minimum motor power required to drive according to the analyzed driving cycle increases from $115 \mathrm{~kW}$ to $310 \mathrm{~kW}$ for a 20 and 94 passenger vehicle, respectively. Concepts with installed power below the curve did not meet the torque and speed requirements.

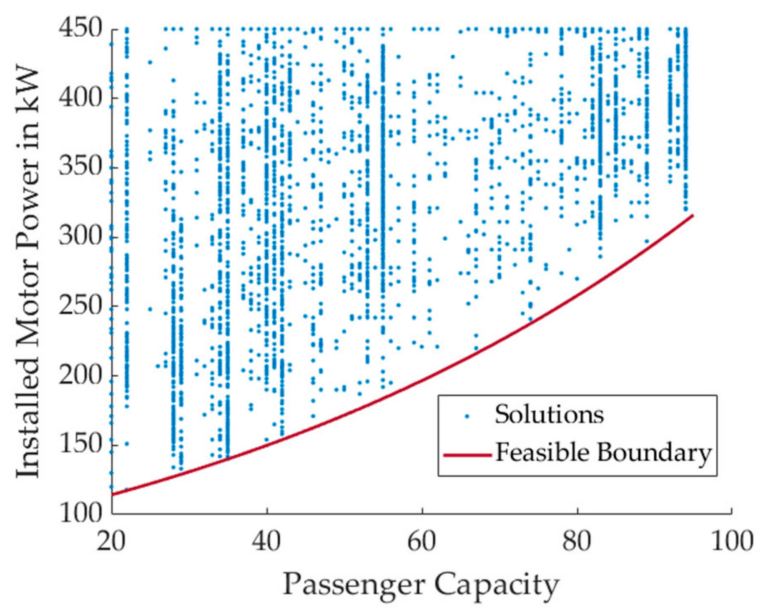

(a)

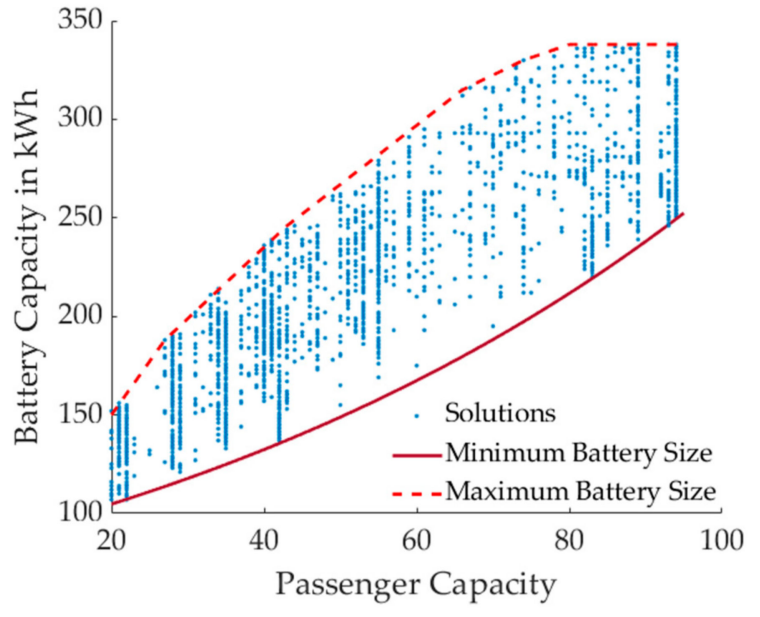

(b)

Figure 13. Shows the solution space and minimum required (a) motor power and (b) battery capacity.

Figure $13 \mathrm{~b}$ shows the minimum battery capacity required for different vehicle sizes. The minimum required battery size increases from $105 \mathrm{kWh}$ for a 20-passenger vehicle to around $250 \mathrm{kWh}$ for a 94-passenger vehicle for the depot charging strategy. The plot further shows the maximum battery size that can be installed and packaged in the vehicle due to the limited packaging space in the underfloor. 


\section{Conclusions}

This paper presents a holistic framework to identify the optimal vehicle specifications of AEBs based on the routes in which the buses will operate. To calculate the optimal specifications, a multi-objective, multi-criteria objective function is formulated by analyzing the requirements from the perspective of the stakeholders. The requirements are categorized into nine properties of service performance, accessibility, comfort, functionality, information, safety, longitudinal dynamics, environmental performance, and costs.

The optimization is formulated with two objectives to find the optimal trade-off between the overall benefit to the stakeholders and the total costs. The first objective maximizes the weighted sum of the properties, while the second objective minimizes the TCO.

To evaluate the objective functions, a simulation framework is developed. The framework derives AEB concepts using a vehicle packaging model. The vehicle's impacts on the properties are subsequently analyzed in a vehicle scheduling, route simulation, LDS, vehicle assignment, lifecycle cost, and lifecycle emissions calculations. The NSGA-II genetic algorithm is used to solve the objective function to find the Pareto optimal solutions.

A case study is conducted using the developed model to find the optimal vehicle specifications of AEBs for a bus route in Singapore. The results showed that the passengers' waiting time could be reduced to around $6 \mathrm{~min}$ using a vehicle size of 20 passengers compared to $18 \mathrm{~min}$ with a 94-passenger vehicle for the analyzed bus route. However, the costs and GHG emissions increase due to the larger fleet required and the longer distances traveled with the 20-passenger vehicle.

Moreover, the parameters for the powertrain design and the battery capacity can be identified through the optimization. For the analyzed case study, the minimum motor size required was found to be $115 \mathrm{~kW}$ for a 20-passenger vehicle and $310 \mathrm{~kW}$ for a 94-passenger vehicle. Similarly, the minimum battery size needed was calculated to be $105 \mathrm{kWh}$ and $250 \mathrm{kWh}$ for the 20 and 94 passenger vehicles, respectively.

Using the proposed model, vehicle manufacturers and bus operators can simulate different scenarios to find the optimal vehicle specifications for their bus routes and analyze the impacts on the benefit to the users, costs, and emissions. Future work will extend the analysis to consider multiple routes and investigate the influence of different charging methods on the vehicle specifications, costs, and emissions.

Author Contributions: A.P. worked on the conceptualization, implementation, and analysis of the results. S.S. was involved in the formulation of the objective function and revising the manuscript. A.O. is the principal investigator of this project and was involved in the supervision of the project. M.L. made an essential contribution to the conception of the research project and revised the paper critically for important intellectual content. M.L. gave the final approval to the version to be published and agrees to all aspects of the work. As guarantor, M.L. accepts responsibility for the overall integrity of the paper. All authors have read and agreed to the published version of the manuscript.

Funding: The research was conducted under the Campus for Research Excellence and Technological Enterprise (CREATE) with the financial support of the Singapore National Research Foundation (NRF).

Conflicts of Interest: The authors declare no conflict of interest. The funders had no role in the design of the study; in the collection, analyses, or interpretation of data; in the writing of the manuscript, or in the decision to publish the results.

\section{References}

1. Wadud, Z. Fully automated vehicles: A cost of ownership analysis to inform early adoption. Transp. Res. Part A Policy Pract. 2017, 101, 163-176. [CrossRef]

2. Greenblatt, J.B.; Saxena, S. Autonomous taxis could greatly reduce greenhouse-gas emissions of US light-duty vehicles. Nat. Clim. Chang. 2015, 5, 860-863. [CrossRef]

3. Azad, M.; Hoseinzadeh, N.; Brakewood, C.; Cherry, C.R.; Han, L.D. Fully Autonomous Buses: A Literature Review and Future Research Directions. J. Adv. Transp. 2019, 2019, 1-16. [CrossRef]

4. Rau, A.; Tian, L.; Jain, M.; Xie, M.; Zhou, Y. Dynamic autonomous road transit (DART) for use-case capacity more than bus. Transp. Res. Procedia 2018, 41, 812-823. [CrossRef] 
5. Project HEAT-Hamburger Hochbahn AG. Available online: https://www.hochbahn.de/hochbahn/hamburg/en/home/ projects/expansion_and_projects/project_heat (accessed on 1 December 2020).

6. Navya. AUTONOM®SHUTTLE: For more fluid mobility. Available online: https://navya.tech/wp-content/uploads/ documents/Brochure_Shuttle_EN.pdf (accessed on 1 December 2020).

7. Easy Mile. An Introduction to the EZ10. Available online: https://coloradotransit.com/wp-content/uploads/2018/10/EasyMileCASTA-Oct-2018.pdf (accessed on 1 December 2020).

8. 2getthere. GRT Vehicle: Automated Minibus-2getthere. Available online: https://www.2getthere.eu/technology/vehicletypes/grt-vehicle-automated-minibus / (accessed on 1 December 2020).

9. Kane, M. Electric, Autonomous and Modular Scania NXT Unveiled. Available online: https://insideevs.com/news/354248 / electric-autonomous-modular-scania-nxt/ (accessed on 1 December 2020).

10. Nicoletti, L.; Romano, A.; König, A.; Schockenhoff, F.; Lienkamp, M. Parametric Modeling of Mass and Volume Effects for Battery Electric Vehicles, with Focus on the Wheel Components. WEVJ 2020, 11, 63. [CrossRef]

11. Fuchs, S.; Lienkamp, M. Parametric Modelling of Mass and Efficiency of New Vehicle Concepts. Atz Worldw 2013, $115,60-67$. [CrossRef]

12. Felgenhauer, M.; Nicoletti, L.; Schockenhoff, F.; Angerer, C.; Lienkamp, M. Empiric Weight Model for the Early Phase of Vehicle Architecture Design. In Proceedings of the 2019 Fourteenth International Conference on Ecological Vehicles and Renewable Energies (EVER), Monte-Carlo, Monaco, 8-10 May 2019; pp. 1-8. [CrossRef]

13. Koenig, A.; Schockenhoff, F.; Koch, A.; Lienkamp, M. Concept Design Optimization of Autonomous and Electric Vehicles. In Proceedings of the 8th International Conference on Power Science and Engineering, (ICPSE 2019), Dublin, Ireland, 2-4 December 2019.

14. Wiedemann, E.; Meurle, J.; Lienkamp, M. Optimization of Electric Vehicle Concepts Based on Customer-Relevant Characteristics; SAE Technical Paper 2012-01-0815; SAE: Warrendale, PA, USA, 2012. [CrossRef]

15. Matz, S. Nutzerorientierte Fahrzeugkonzeptoptimierung in Einer multimodalen Verkehrsumgebung. Ph.D. Thesis, Technische Universität München, München, Germany, 2015.

16. Kuchenbuch, K. Methodik zur Identifikation und zum Entwurf Packageoptimierter Elektrofahrzeuge. Ph.D. Thesis, Technische Universität Braunschweig, Braunschweig, Germany, 2012.

17. Holjevac, N.; Cheli, F.; Gobbi, M. Multi-objective vehicle optimization: Comparison of combustion engine, hybrid and electric powertrains. Proc. Inst. Mech. Eng. Part D J. Automob. Eng. 2020, 234, 469-487. [CrossRef]

18. Lin, X.; Kerler, M.; Birke, K.P.; Lienkamp, M. Optimal Battery Cell Design for Electric Vehicles-A Holistic Method with Consideration of Ageing due to Electrothermal Gradients. In Proceedings of the 8th International Conference on Power Science and Engineering, (ICPSE 2019), Dublin, Ireland, 2-4 December 2019; ISBN 9781728160818.

19. Angerer, C.; Krapf, S.; Buß, A.; Lienkamp, M. Holistic modeling and optimization of electric vehicle Powertrains considering longitudinal performance, vehicle Dynamics, costs and energy consumption. In Proceedings of the ASME 2018 International Design Engineering Technical Conferences and Computers and Information in Engineering Conference, Quebec City, QC, Canada, 26-29 August 2018.

20. Schönknecht, A.; Babik, A.; Rill, V. Electric Powertrain System Design of BEV and HEV Applying a Multi Objective Optimization Methodology. Transp. Res. Procedia 2016, 14, 3611-3620. [CrossRef]

21. Scholl, M.; Minnerup, K.; Reiter, C.; Bernhardt, B.; Weisbrodt, E.; Newiger, S. Optimization of a Thermal Management System for Battery Electric Vehicles. In Proceedings of the 2019 Fourteenth International Conference on Ecological Vehicles and Renewable Energies (EVER), Monte-Carlo, Monaco, 8-10 May 2019; pp. 1-10. [CrossRef]

22. Fries, M.; Lehmeyer, M.; Lienkamp, M. Multi-criterion optimization of heavy-duty powertrain design for the evaluation of transport efficiency and costs. In Proceedings of the IEEE 20th International Conference on Intelligent Transportation Systems, Yokohama, Japan, 16-19 October 2017.

23. Ziemann. Zielsystemmanagement für die Produktentstehung von PKW; Books on Demand: Norderstedt, Germany, 2007.

24. Meurle, J.; Rigel, S.; Muigg, A. Fahrzeugeigenschaften-Erwartungshaltung des Kunden und Technische Umsetzbarkeit; Zenloop: Graz, Austria, 2009.

25. Weber, J. Automotive Development Processes; Springer: Berlin/Heidelberg, Germany, 2009; ISBN 978-3-642-01252-5.

26. Schockenhoff, F.; König, A.; Koch, A.; Lienkamp, M. Customer-Relevant Properties of Autonomous Vehicle Concepts. Procedia CIRP 2020, 91, 55-60. [CrossRef]

27. Wiedemann, E. Ableitung von Elektrofahrzeugkonzepten aus Eigenschaftszielen. Ph.D. Thesis, Technische Universität München, München, Germany, 2013.

28. Moataz, M.; Ryan, G.; Mark, F.; Pavlos, K. Electric buses: A review of alternative powertrains. Renew. Sustain. Energy Rev. 2016, 62, 673-684. [CrossRef]

29. Lajunen, A. Energy consumption and cost-benefit analysis of hybrid and electric city buses. Transp. Res. Part C Emerg. Technol. 2014, 38, 1-15. [CrossRef]

30. Harris, A.; Soban, D.; Smyth, B.M.; Best, R. A probabilistic fleet analysis for energy consumption, life cycle cost and greenhouse gas emissions modelling of bus technologies. Appl. Energy 2020, 261, 114422. [CrossRef]

31. Lajunen, A. Lifecycle costs and charging requirements of electric buses with different charging methods. J. Clean. Prod. 2018, 172, 56-67. [CrossRef] 
32. Kunith, A.; Mendelevitch, R.; Goehlich, D. Electrification of a city bus network-An optimization model for cost-effective placing of charging infrastructure and battery sizing of fast-charging electric bus systems. Int. J. Sustain. Transp. 2017, 11, 707-720. [CrossRef]

33. Teichert, O.; Chang, F.; Ongel, A.; Lienkamp, M. Joint Optimization of Vehicle Battery Pack Capacity and Charging Infrastructure for Electrified Public Bus Systems. IEEE Trans. Transp. Electrif. 2019, 5, 672-682. [CrossRef]

34. van Kooten Niekerk, M.E.; van den Akker, J.M.; Hoogeveen, J.A. Scheduling electric vehicles. Public Transp. 2017, 9, 155-176. [CrossRef]

35. Wang, Y.; Huang, Y.; Xu, J.; Barclay, N. Optimal recharging scheduling for urban electric buses: A case study in Davis. Transp. Res. Part E Logist. Transp. Rev. 2017, 100, 115-132. [CrossRef]

36. Nicoletti, L.; Bronner, M.; Danquah, B.; Koch, A.; Konig, A.; Krapf, S.; Pathak, A.; Schockenhoff, F.; Sethuraman, G.; Wolff, S.; et al Review of Trends and Potentials in the Vehicle Concept Development Process. In Proceedings of the 2020 Fifteenth International Conference on Ecological Vehicles and Renewable Energies (EVER), Monte-Carlo, Monaco, 10-12 September 2020; pp. 1-15. [CrossRef]

37. Scheuermann, S. Development of a Customer-Centric Approach to Derive Autonomous Electric Vehicle Concepts for Public Transportation in Singapore. Master's Thesis, Technical University of Munich, Munich, Germany, 2020.

38. Aigner, J. Zur zuverlässigen Beurteilung von Fahrzeugen. ATZ Automobiltechnische Zeitschrift 1982, 84, 447-450.

39. Sethuraman, G.; Schwarz, M.; Maxl, S.; Ongel, A.; Lienkamp, M.; Ng, H.W.; Raksincharoensak, P. Development of an Overall Vehicle Sizing and Packaging Tool for Autonomous Electric Buses in the Early Concept Phase. SAE Int. J. Commer. Veh. 2020, 13, 23-42. [CrossRef]

40. Nicoletti, L.; Mayer, S.; Brönner, M.; Schockenhoff, F.; Lienkamp, M. Design Parameters for the Early Development Phase of Battery Electric Vehicles. WEVJ 2020, 11, 47. [CrossRef]

41. Deb, K.; Pratap, A.; Agarwal, S.; Meyarivan, T. A fast and elitist multiobjective genetic algorithm: NSGA-II. IEEE Trans. Evol. Comput. 2002, 6, 182-197. [CrossRef]

42. Pesce, T. Ein Werkzeug zur Spezifikation von Effizienten Antriebstopologien für Elektrofahrzeuge. Ph.D. Thesis, Technische Universität München, München, Germany, 2014.

43. Seeger, F. Energetische Modellierung Verschiedener Systeme zur Momentenverteilung für ein Adaptives Antriebsstrangmodell. Semester Thesis, Technische Universität München, München, Germany, 2017.

44. Friedrichshafen, Z.F. Axle \& Transmission Systems for Buses. Available online: https://www.zf.com/master/media/corporate/ m_zf_com/company/download_center/products / trucks /2020_3/TU_Product_Overview_202012_DE_EN_LowRes.pdf (accessed on 15 December 2020).

45. Sethuraman, G.; Tran, P.R.; Ongel, A.; Lienkamp, M.; Raksincharoensak, P. Development of a parametric packaging and sizing tool for autonomous electric bus system. Proc. Inst. Mech. Eng. Part D J. Automob. Eng. 2020. [CrossRef]

46. Ceder, A.; Hassold, S.; Dano, B. Approaching even-load and even-headway transit timetables using different bus sizes. Public Transp. 2013, 5, 193-217. [CrossRef]

47. Sun, L.; Tirachini, A.; Axhausen, K.W.; Erath, A.; Lee, D.-H. Models of bus boarding and alighting dynamics. Transp. Res. Part A Policy Pract. 2014, 69, 447-460. [CrossRef]

48. Pathak, A.; Sethuraman, G.; Krapf, S.; Ongel, A.; Lienkamp, M. Exploration of Optimal Powertrain Design Using Realistic Load Profiles. World Electr. Veh. J. 2019, 10, 56. [CrossRef]

49. Ongel, A.; Loewer, E.; Roemer, F.; Sethuraman, G.; Chang, F.; Lienkamp, M. Economic Assessment of Autonomous Electric Microtransit Vehicles. Sustainability 2019, 11, 648. [CrossRef]

50. Fries, M.; Kerler, M.; Rohr, S.; Sinning, M.; Schickram, S.; Lienkamp, M.; Kochhan, R.; Fuchs, S.; Reuter, B.; Burda, P.; et al. An Overview of Costs for Vehicle Components, Fuels, Greenhouse Gas Emissions and Total Cost of Ownership-Update 2017. Res. Gate 2017. [CrossRef]

51. Fuchs, S. Verfahren zur Parameterbasierten Gewichtsabschätzung neuer Fahrzeugkonzepte. Ph.D. Thesis, Technische Universität München, München, Germany, 2014.

52. Energy Market Authority. Singapore Energy Statistics-Energy Prices. Available online: https://www.ema.gov.sg/singaporeenergy-statistics/Ch05/index5 (accessed on 16 December 2020).

53. Sethuraman, G. Vehicle Component Configuration Design and Packaging in Virtual Environment for Autonomous Electric Buses. Ph.D. Thesis, Tokyo University of Agriculture and Technology, Tokyo, Japan, 2020.

54. Umberto LCA+. Umberto LCA+. Available online: https://www.ifu.com/en/umberto/lca-software/ (accessed on 8 May 2020).

55. Ecoinvent. Ecoinvent 3.5. Available online: https://www.ecoinvent.org/database/olderversions/ecoinvent-35/ecoinvent-35 .html (accessed on 3 February 2019).

56. Pathak, A.; Sethuraman, G.; Ongel, A.; Lienkamp, M. Impacts of electrification \& automation of public bus transportation on sustainability-A case study in Singapore. Forsch. Ing. 2020. [CrossRef]

57. EMA Supply. Energy Market Authority I Energy Supply. Available online: https://www.ema.gov.sg/cmsmedia/Publications_ and_Statistics/Publications/ses/2018/energy-supply/index.html (accessed on 7 May 2020).

58. Kelly, S.; Apelian, D. Automotive Aluminum Recycling at End of Life: A Grave-to-Gate Analysis. Available online: http:/ / www.drivealuminum.org/wp-content/uploads/2016/06/Final-Report-Automotive-Aluminum-Recycling-at-End-ofLife-A-Grave-to-Gate-Analysis.pdf (accessed on 16 December 2020). 
59. LithoRec II. Recycling of EV-Lithium-Ion-Batteries. Available online: http:/ / www.lithorec2.de/index.php/en/ (accessed on 1 October 2019).

60. McGlothlin, S. Copper Recycling Process Technology in End of Life Vehicle (ELV) Shredder Plants. Available online: https: //www.metalbulletin.com/events/download.ashx/document/speaker/6539/a0ID000000X0jUWMAZ/Presentation (accessed on 1 October 2019).

61. WorldAutoSteel. Recycling. Available online: https://www.worldautosteel.org/life-cyclethinking/recycling/ (accessed on 2 July 2019).

62. Lai, J.; Yu, L.; Song, G.; Guo, P.; Chen, X. Development of City-Specific Driving Cycles for Transit Buses Based on VSP Distributions: Case of Beijing. J. Transp. Eng. 2013, 139, 749-757. [CrossRef] 